Revistade
Economild
Contemporâned

\title{
A RELAÇÃO ENTRE PREÇO E DEMANDA POR JOGOS DE FUTEBOL NO BRASIL
}

\author{
Bruno Ítalo Lima Benevides ${ }^{a}$ \\ Sandra Maria dos Santos ${ }^{b}$ \\ Augusto Cézar de Aquino Cabral

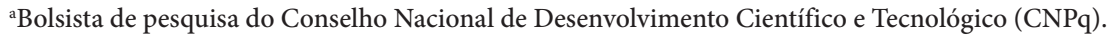

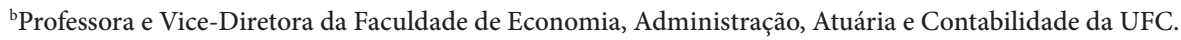 \\ 'Professor do Mestrado Profissional em Administração e Controladoria e Diretor da \\ Faculdade de Economia, Administração, Atuária e Contabilidade da UFC. \\ Artigo recebido em 25/04/2016 e aprovado em 04/08/2017. \\ RESUMO: A indústria do futebol chega a movimentar em todo mundo, por ano, de \\ acordo com Belo e Paolozzi (2013), um valor entre US\$ 400 bilhões e US\$ 1 trilhão. \\ Como atividade econômica, tem atraído a atenção de diversos estudos acadêmicos \\ (DOBSON e GODDARD, 2001; SOUZA, 2004 e MADALOZZO, 2008). Entre os re- \\ sultados obtidos nesses estudos, tem-se divergências com relação à variável preço nas \\ equações de demanda por futebol. Dessa forma, este estudo objetiva identificar a re- \\ lação entre preço e demanda por futebol. Foram utilizados dados secundários a partir \\ do IBGE, da CBF e da Pluri Consultoria. A pesquisa faz uma análise a partir de 380 \\ jogos do campeonato brasileiro. Para estimação da demanda utilizou-se o método de \\ MQO. O modelo teve como variável dependente o público pagante presente nos está- \\ dios. Os resultados evidenciaram que a função demanda é não homogênea.
}

PALAVRAS-CHAVE: futebol; demanda; cadeia produtiva.

CLASSIFICAÇÃO JEL: C1; D1.

Correspondência para: Bruno Ítalo Lima Benevides

Contato: brunoitalobenevides@yahoo.com.br 


\title{
THE RELANTIONSHIP BETWEEN PRICE AND DEMAND FOR FOOTBALL MATCHES IN BRAZIL
}

\begin{abstract}
The football industry moves around the world every year, according to Belo and Paolozzi (2013), worth between $\$ 400$ billion and \$ 1 trillion. As an economic activity, it has attracted the attention of several academic studies (DOBSON and GODDARD, 2001; SOUZA, 2004 and MADALOZZO, 2008). Among the results obtained in these studies, there are differences regarding the price variable in the demand equations for soccer. Thus, this study aims to identify the relationship between price and demand for soccer. Secondary data were used from IBGE, CBF and Pluri Consultoria. The search does an analysis of 380 games of the Brazilian championship. To estimate the demand, the OLS method was used. The dependent variable was the dependent model present in the stadiums. The results showed that the demand function is inhomogeneous.
\end{abstract}

KEYWORDS: football; demand; supply chain. 


\section{INTRODUÇÃO}

O futebol, esporte mais difundido do mundo, é um dos ramos esportivos que tem despertado a atenção como atividade econômica. Nesta perspectiva, como afirma Cragnotti (apud DUCREY et al., 2003, p. 31), "Football is the most global business of the world in a time of globalization and triumph of leisure. What other good has been bought by three billion consumers? Not even Coca-Cola!".

A indústria do futebol chega a movimentar em todo mundo, por ano, de acordo com Belo e Paolozzi (2013), um valor entre US\$ 400 bilhões e US\$ 1 trilhão, o que representa cerca de $18 \%$ e $44 \%$, respectivamente, do PIB brasileiro. Contudo, no Brasil, apesar de sua imensa popularidade, esse esporte movimenta, segundo relatório da Pluri Consultoria (2012), cerca de R $\$ 36$ bilhões por ano, o que representa menos de $1 \%$ do valor global, enquanto na Inglaterra o valor chega a ser de $30 \%$. Portanto, no Brasil, como atividade econômica, o futebol está longe de ter sua eficiência maximizada, mesmo sendo reconhecido como o esporte da nação.

Para avaliar a potencialidade econômica de um determinado setor, como o futebol, é necessário analisar o número de consumidores e a propensão que os mesmos têm a consumir do bem produzido pela indústria em questão. Desse modo, fica evidenciada a relevância em fazer uma análise do comportamento do consumidor de futebol e entender os fatores que o levam a demandar este bem, para que, desta forma, essa indústria possa funcionar de maneira mais eficiente na perspectiva econômica.

Com relação aos estudos da demanda por futebol, diversos pesquisadores têm baseado seus estudos utilizando o público presente nos estádios como proxy para a demanda do torcedor. Entre os fatores explicativos para essa procura, geralmente, encontram-se fatores econômicos e estruturais, além de incerteza do resultado e qualidade esperada da partida. Com relação aos estudos mencionados estão Souza (2004), Madolozzo (2008) e Bortoluzo, Laropoli e Machado (2011) no Brasil. Dobson e Goddard (2001) e Buraimo e Simmons (2006) na Inglaterra, e García e Rodríguez (2001) na Espanha.

No entanto, a maioria dos estudos envolvendo a Economia do Futebol, como bem afirmam García e Rodríguez (2001), não inclui o preço como variável explicativa. Uma explicação para a exclusão desta variável tão importante na teoria microeconômica é a possível endogeneidade do preço.

Desta forma, dada a importância da identificação dos determinantes da demanda por futebol, bem como da análise da elasticidade preço da demanda, este trabalho tem a seguinte pergunta de partida: qual a relação entre o preço e a demanda por jogos de futebol? 
Tem-se as seguintes hipóteses: a) a função demanda por futebol é não homogênea nos preços; e b) fatores econômicos, estruturais, de qualidade da partida e incerteza do resultado afetam a demanda por jogos de futebol.

Como objetivo principal este trabalho visa a identificar a relação entre os fatores econômicos e a demanda por jogos de futebol no Brasil. Como objetivos específicos, tem-se: i) identificar os fatores determinantes da demanda por jogos de futebol no Brasil; ii) verificar o impacto dos novos estádios construídos para a Copa do Mundo na procura por partidas de futebol e iii) identificar o impacto dos fatores econômicos, estruturais, substitutos e de qualidade da partida na demanda por futebol.

O estudo utiliza-se de um modelo econométrico, em alinhamento ao argumento de Souza (2004) de que pesquisas envolvendo a demanda por jogos de futebol seguem um padrão, em que tal modelo é formulado para tentar explicar a demanda de acordo com uma série de fatores. Em termos de estrutura, além desta introdução, esse artigo tem quatro outras seções. A seção 2 apresenta pesquisas desenvolvidos na área da Economia do futebol. A seção 3 traz a metodologia utilizada, enquanto a seção 4 faz uma análise dos resultados obtidos. Por fim, a seção 5 apresenta as conclusões do estudo.

\section{A ECONOMIA DO FUTEBOL}

O interesse acadêmico na economia do esporte de times profissionais data de meados da década de 1950, quando Rottenberg (1956) analisou o mercado de trabalho do baseball americano. Desde então, vários livros e artigos foram publicados a respeito. Nesta seção, tendo em vista o objeto do estudo, são apresentadas pesquisas sobre a demanda por futebol.

\subsection{ESTUDOS SOBRE A DEMANDA POR FUTEBOL}

Demanda é a quantidade de um bem que os consumidores desejam consumir a um determinado preço; contudo, a quantidade demandada de um bem pode não depender apenas do preço, mas também de outras variáveis (PINDYCK e RUBINFELD, 2009). Renda é uma variável importante, pois, com uma renda maior, os consumidores poderão adquirir mais bens. Em relação aos jogos de futebol, além do preço e da renda, como afirma Souza (2004), aspectos referentes à partida, como desempenho recente dos times, estrutura do estádio e horário em que essa ocorre, também são importantes para explicar a procura por esse bem. 
Nos estudos sobre a demanda por futebol, Dobson e Goddard (2001), Forrest e Simmons (2006), Buraimo e Simmons (2006) e O'Connor (2009) estimaram uma equação de demanda para o campeonato inglês. Para o campeonato brasileiro, Souza (2004), Madalozzo (2008) e Bortoluzzo, Laropoli e Machado (2011) também fizeram esta estimação. Já na Espanha, tem-se o estudo de García e Rodríguez (2001).

Dobson e Goddard (2001) estimaram um modelo buscando explicar as variações nas médias de público, por temporada, ao nível de clube do campeonato inglês, incluindo as quatro divisões, entre as temporadas de 1947 e 1997. Os autores modelaram a demanda em dois momentos. No primeiro, o modelo foi estimado utilizando dados em painel.

The model's coefficients reflect the influence of four factors upon demand: loyalty in the short-term (or persistence in attendance from year to year), success (measured by league position), admission price and entertainment (proxied by goals scored). (DOBSON e GODDARD, 2001, p. 342)

Já, no segundo momento, os autores tentaram explicar “... the cross-sectional variation between clubs in their base levels of attendance, and their short-term loyalty, success, price and entertainment coefficients obtained at the first stage" (DOBSON e GODDARD, 2001, p. 343). Nesta etapa, os autores usaram como variáveis explicativas características socioeconômicas e demográficas da cidade de cada clube. Foram utilizados, por exemplo, o tamanho da população, a estrutura ocupacional e o desemprego, além de características relacionadas ao futebol, como a idade do time e o número de outros times na mesma cidade.

Os resultados obtidos pelos autores no primeiro estágio mostraram-se significantes ao nível de $5 \%$, exceto a variável referente aos gols marcados, que se mostrou insignificante no modelo. Dobson e Goddard (2001) ainda concluem que, devido ao fato de o público estar em logaritmo e todas as variáveis estarem padronizadas, os coeficientes estimados não têm uma interpretação direta. Assim, pode-se concluir que os resultados obtidos apenas mostram se os fatores que buscam explicar a demanda têm impacto positivo ou negativo, sem, contudo, fornecer a elasticidade destes fatores.

No segundo estágio, Dobson e Goddard (2001) utilizaram como variáveis explicativas o logaritmo natural da população e do número de anos do clube. Foram utilizados também o número de outros clubes presentes na mesma cidade, a porcentagem de empregados na agricultura, assim como a porcentagem de empregados nos setores de energia, manufatura e construção. Além disso, foi utilizado o número de homens com idade entre 16 e 64 anos desempregados. Como variáveis independentes, os autores utilizaram o público, preço, lealdade em curto prazo, posição na liga e gols marcados. Os resultados foram, todos, significantes ao nível de $5 \%$. 
Para estimar a demanda do campeonato inglês, Buraimo e Simmons (2006) também utilizaram um modelo econométrico, em que a procura por jogos é função de seis grupos de fatores: fidelidade ao time, qualidade dos times envolvidos na partida, incerteza do resultado, tamanho do mercado, competição e mídia. Os autores estimaram o modelo econométrico utilizando TOBIT e obtiveram resultados estatisticamente não-significantes apenas para as variáveis referentes à qualidade dos times envolvidos na partida, como idade do time visitante, bem como seu número de pontos, e referente à mídia, como partidas transmitidas no Bank Holiday, e período em que a partida ocorreu.

O'Connor (2009) buscou estimar a lealdade dos torcedores ingleses utilizando uma equação de demanda para verificar se fatores como o momento atual do time e promoções para outras divisões afetam a procura por jogos. Como variável dependente, utilizou a porcentagem de lotação do estádio dada pela relação entre público presente e capacidade do estádio.

O’Connor (2009) não dividiu os fatores explicativos da demanda em grupo. Utilizou-se das seguintes variáveis: posição do time até a data de realização da partida, preço dos ingressos, número de gols que o time tenha sofrido nos últimos três jogos, bem como tenha feito, porcentagem de jogos já realizados no campeonato, quadrado da posição do time, quadrado da porcentagem de partidas realizadas e dummies, caso o time tenha sido promovido, rebaixado, vencido pelo menos um dos últimos três jogos, perdido pelo menos um dos últimos três jogos, se o jogo foi realizado na semana e, por último, se envolvia times rivais.

O autor estimou o modelo de três maneiras, efeitos fixos, aleatórios e mínimos quadrados. Os dois primeiros modelos mostraram resultados semelhantes, sendo estatisticamente significantes a porcentagem de jogos já realizados, o quadrado da porcentagem de jogos realizados, rebaixamento, promoção, partida realizada em dias de semana e envolvendo rivais. Já pelo método de MQO, apenas promoção, partidas envolvendo rivais e a porcentagem de jogos já realizadas foram significantes.

García e Rodríguez (2001), por sua vez, estimaram uma equação de demanda para primeira divisão do campeonato espanhol, para o período entre 1992 e 1996. Os autores utilizaram dados em painel e também observaram a possível endogeneidade da variável preço, estimando o modelo por mínimos quadrados de dois estágios.

Como variáveis explicativas, os autores utilizaram o preço mais barato do ingresso, deflacionado pelo Consumer Price Index (CPI), a renda per capita real da cidade em que jogo foi realizado e o tamanho da população desta cidade. No que se refere a qualidade esperada do jogo, os autores utilizaram os orçamentos dos dois clubes participantes de cada partida, o número de jogadores que jogaram por seleções, duas dummies para caso o time visitante seja Barcelona ou Real Madrid (os dois clubes mais 
importantes da Espanha), dummy para captar o efeito da rivalidade entre os clubes e finalmente um dummy para jogos em que os torcedores que possuíam carnês tiveram que pagar ingresso, uma prática que acontece frequentemente na Espanha e chamada de club day match.

Ainda com relação à qualidade esperada da partida, os autores incluíram variáveis como o número de vitórias do time da casa nos últimos três jogos, a posição deste time na tabela, um dummy para caso o clube visitante não tenha perdido nos últimos quatro jogos e duas dummies, uma para caso o time da casa não tenha mais chance de vencer o campeonato e outra para caso não haja chance desse time deixar a zona de rebaixamento.

Com respeito aos fatores que medem a incerteza do resultado, os autores usaram o quadrado da diferença entre as posições do time mandante e visitante e um dummy com valor 1 para caso o clube da casa esteja até três posições a frente ou cinco atrás do time visitante.

Por último, García e Rodríguez (2001) utilizaram variáveis para capturar o custo de oportunidade de ir a um jogo de futebol. Os autores incluíram fatores como a distância entre as cidades do time mandante e visitante, o clima (se estava chovendo ou não), além de partidas televisionadas.

Os autores analisaram o possível problema de endogeneidade da variável preço, assim estimaram um modelo de variável instrumental, utilizando como variáveis explanatórias para o logaritmo do preço todas as variáveis utilizadas na equação de demanda, acrescentando instrumentos referentes à performance dos clubes na temporada passada, como a posição final do time mandante e visitante no campeonato anterior, além de dummies para caso os times tenham vindo da segunda divisão e o número de ingressos que poderiam ser vendidos, ou seja, a capacidade do estádio em que a partida ocorreu.

Os coeficientes estimados pelos autores mostraram-se significantes ao nível de 5\%. Como resultados, García e Rodríguez (2001) encontraram também elasticidade-preço da demanda igual a -0,63. Com relação à elasticidade-renda, os autores observaram um resultado divergente da literatura até aqui apresentada, o valor de 0,51 mostra que o futebol na Espanha é um bem normal, enquanto para estudos realizados para os campeonatos inglês e brasileiro este bem mostrou ser inferior.

Já Souza (2004) objetivou verificar os fatores mais importantes que influenciam a decisão dos torcedores de comparecerem aos estádios, fazendo uma análise do campeonato brasileiro de 2002. O autor também verificou se os jogos televisionados constituem um bem substituto dos jogos nos estádios de futebol e tentou medir as elasticidades preço e renda da demanda.

Souza (2004) também se utilizou de um modelo econométrico, em que a variável dependente consiste no público pagante de cada partida. Quanto às variáveis explica- 
tivas, o autor as divide em seis grupos de fatores que influenciam a demanda: fatores econômicos, demográficos, desequilíbrio competitivo, qualidade esperada da partida, substitutos e atributos dos clubes. O autor estimou seu modelo de três formas, uma linear, outra log-linear e uma log-log. Segundo ele, o modelo linear apresenta vários problemas, como heterocedasticidade e não normalidade dos resíduos, além de revelar erro de especificação. O modelo log-log foi testado para capturar a elasticidade da renda. Foram obtidos resultados significantes ao nível de 5\% para as variáveis, exceto aquelas referentes ao desemprego e as partidas televisionadas. Sobre a elasticidade renda da demanda, Souza (2004) conclui que os jogos do campeonato brasileiro de 2002 são bens inferiores, apresentando uma elasticidade de -3,67.

Conforme Madalozzo (2008), a demanda por jogos é frequentemente alvo de estudos na economia dos esportes. A abordagem mais comum é uma equação de demanda com fatores econômicos e sociais que determinam a procura para cada tipo de esporte.

Em seu estudo, Madalozzo (2008) investigou os fatores que afetaram a demanda por jogos do campeonato brasileiro entre 2003 e 2006. Tendo analisado 1946 jogos, a autora usou o logaritmo do público pagante como variável dependente. O modelo foi estimado usando dados em painel com efeitos fixos e aleatórios. A autora também dividiu os fatores que afetam a demanda em grupos, sendo eles: características estruturais, qualidade esperada, performance e incerteza do resultado.

Os modelos estimados por efeitos fixos e aleatórios tiveram resultados similares. Em ambos, as variáveis referentes ao grupo estrutural mostram-se ser significantes a 5\%, exceto para o número de jogos disputados pelo time da casa no último mês. Além disso, a renda não foi estimada por efeito fixo, apenas aleatório, apresentando uma elasticidade de - 0,7 , mostrando que o futebol é um bem inferior. Já o preço obteve valor igual para os dois modelos, tendo uma elasticidade de -0,24, o que implica, segundo a autora, que, considerando cada time como monopolista, esse não é maximizador de lucro.

Nos fatores referentes à qualidade esperada da partida, as variáveis alusivas aos títulos estaduais e títulos internacionais no ano anterior mostram-se insignificantes. Neste grupo, a variável relativa à rivalidade mostrou ter um impacto de 0,63 na demanda por jogos do campeonato brasileiro. No grupo performance, apenas a variável referente aos pontos ganhos pelo time visitante nos últimos três jogos mostrou-se insignificante. Já no grupo incerteza, a diferença entre a posição dos times adversários e a chance de ir para copa libertadores obtiveram resultados insignificantes.

Bortoluzzo, Laropoli e Machado (2011) examinaram a demanda por jogos do campeonato brasileiro de futebol da série A no período de 2004 a 2009, também usando o público pagante como variável dependente e estimando o modelo por TOBIT. Os dados são de 2481 jogos do campeonato brasileiro da primeira divisão. Como variá- 
veis independentes, usaram a renda per capita anual da cidade em que o jogo ocorreu, a população da respectiva cidade, classificação do time da casa e do time visitante, pontos ganhos pelo time da casa e visitante nos últimos três jogos, gols marcados pelo time mandante e visitante nas três partidas anteriores, preço médio (dado pela razão entre a arrecadação e o público pagante), e dummies para: estação do ano, caso o jogo tenha ocorrido no fim de semana, caso tenho chovido, se o jogo foi realizado às $21 \mathrm{~h}$, se o jogo é considerado clássico, se há time de São Paulo ou Rio de Janeiro e se o jogo foi disputado no início, meio ou fim do campeonato.

Cinco variáveis do modelo mostraram-se insignificantes: pontos ganhos pelo time visitante nas últimas três partidas, gols marcados pelo time visitante nos últimos três jogos, dummy para o caso de o jogo ter ocorrido às $21 \mathrm{~h}$, dummy para o caso de o jogo ter ocorrido no inverno e dummy para o caso de o jogo ter ocorrido na primavera. Com relação às variáveis econômicas, os autores encontraram uma elasticidade-preço de -0,21 e uma elasticidade-renda da demanda de -0,47.

Nota-se nesta seção que fatores econômicos, estruturais e de qualidade da partida são comuns nos estudos sobre a demanda por futebol. O Quadro 1 mostra um resumo com os resultados mais importantes trazidos pelos estudos citados acima.

\section{Quadro 1 - Síntese dos resultados de estudos sobre economia do futebol}

\begin{tabular}{|l|c|c|}
\hline Variáveis explicativas & Referencial teórico & Resultados obtidos respectivamente \\
\hline $\begin{array}{l}\text { Log } \\
\text { (Preço) }\end{array}$ & $\begin{array}{c}\text { Dobson e Goddard (2001); García e Rodríguez } \\
(2001) ; \text { Madalozzo (2008); e Bortoluzzo, Laropoli e } \\
\text { Machado (2011) }\end{array}$ & $-0,91 ;-0,63 ;-0,24 ;-0,21$ \\
\hline $\begin{array}{l}\text { Log } \\
\text { (Renda) }\end{array}$ & $\begin{array}{c}\text { García e Rodríguez (2001); Souza (2004); Mada- } \\
\text { lozzo (2008); e Bortoluzzo, Laropoli e Machado } \\
(2011)\end{array}$ & 0,$51 ;-3,67 ;-0,70 ;-0,47 ;$ \\
\hline Rival & $\begin{array}{c}\text { Souza (2004); Madalozzo (2008); e Bortoluzzo, } \\
\text { Laropoli e Machado (2011) }\end{array}$ & 0,$74 ; 0,62 ; 0,42$ \\
\hline Grande & $\begin{array}{c}\text { Souza (2004); Madalozzo (2008); e Bortoluzzo, } \\
\text { Laropoli e Machado (2011) }\end{array}$ & 0,$32 ; 0,30 ; 0,26$ \\
\hline
\end{tabular}

Fonte: Elaboração própria.

\section{METODOLOGIA}

\subsection{TIPOLOGIA DE PESQUISA}

A pesquisa é de natureza explicativa e descritiva. Quanto ao caráter explicativo, esse tipo de pesquisa "tem como propósito identificar fatores que determinam ou contribuem para a ocorrência dos fenômenos" (GIL, 2010, p. 43). Sendo assim, dado que se busca verificar os fatores determinantes da demanda por jogos do campeonato brasileiro de futebol da série A de 2013, justifica-se o caráter explicativo do estudo. A natu- 
reza descritiva decorre do fato de que "visa descrever as características de determinada população ou fenômeno ou o estabelecimento de relações entre as variáveis" (SILVA e MENEZES, 2001, p. 21). Neste contexto, essa pesquisa é descritiva, pois faz uma descrição das características daqueles fatores.

Além disso, trata-se de um estudo quantitativo, haja vista que os dados utilizados receberam tratamento estatístico (RICHARDSON, 2007) que possibilitaram verificar os determinantes que afetam a demanda por jogos do campeonato brasileiro da série A.

\subsection{BASE DE DADOS}

Esta pesquisa se baseia em dados secundários gerados a partir do banco de dados do Instituto Brasileiro de Geografia e Estatística (IBGE), Confederação Brasileira de Futebol (CBF), Pluri Consultoria e do Cadastro Nacional de Estádios de Futebol, através da Internet em seus respectivos sites oficiais. A pesquisa faz uma análise a partir dos 380 jogos ocorridos na temporada de 2013, no Brasil. Todos os dados dessa pesquisa são referentes ao ano de 2013, exceto o rendimento médio dos domicílios, disponibilizado pelo IBGE, que é referente ao ano de 2010.

\subsection{MODELO ECONOMÉTRICO}

Como afirma Souza (2004), pesquisas envolvendo a demanda por jogos de futebol seguem um padrão em que um modelo econométrico é formulado para tentar explicar a demanda de acordo uma série de fatores. Tal argumento é reforçado por Dobson e Goddard (2001) ao afirmarem que muitos estudos analisam o público, estimando um modelo de regressão e interpretando o resultado como uma equação de demanda. Nesta linha de ação, este estudo também se utiliza de um modelo econométrico.

A variável dependente utilizada no estudo é dada pelo número de pagantes de ingressos para jogos do campeonato brasileiro. A variável foi posta sobre a forma logarítmica, sob a hipótese de não linearidade com as variáveis independentes. O público pagante é usado, pois "provide the main source of data for the dependent variable in econometric models of the demand for football attendance" (DOBSON e GODDARD, 2001, p. 319).

Quanto às variáveis explicativas, parte-se do pressuposto que a demanda é função de quatro grupos de fatores, sendo eles: econômicos, de qualidade esperada da partida, incerteza do resultado e estruturais. 
Entre os fatores econômicos, foram utilizados o logaritmo de preço médio, dado pela razão entre arrecadação, e público pagante. Ainda neste grupo de fatores, foi utilizado o rendimento médio das famílias na cidade em que a partida ocorreu.

Já no grupo de fatores relacionados à qualidade esperada da partida para o futebol brasileiro estão as variáveis: Rival, Vitória, Grande, Promovido, Rodada, Posição, Pontos, Amplitude, e Libertadores.

No grupo de substitutos para o Brasil foi utilizada a variável PFC.

Por último, entre os fatores estruturais estão as variáveis Log (Capacidade), Log (Torcida), Arenas e Log (Passagem) para o Brasil.

Com relação às variáveis econômicas preço e renda, essas são utilizadas com base na teoria microeconômica, pois, como afirmam Pindyck e Runbifeld (2009), estes fatores são determinantes da demanda dos consumidores.

Será utilizado também o quadrado da variável preço sob a hipótese de que a relação entre preço e demanda é não-linear. Isso porque, segundo Varian (2006), a hipótese de linearidade do preço em relação à demanda é muito simplista para uma análise do mundo real, servindo apenas para facilitar as aplicações matemáticas ligadas à economia. Dessa forma, este trabalho tentará verificar como se comporta o preço do futebol no mundo real.

Os times rivais encontram-se em um mesmo território, como cidade ou estado. Assim, será utilizada uma variável dummy com valor 1 caso os times sejam da mesma cidade e 0 caso contrário. Esta variável será utilizada, pois, de acordo com Madalozzo (2008), os jogos entre times rivais geralmente são entre times da mesma cidade, o que faz com que fãs de ambos possam ir ao estádio, aumentando, dessa forma, o público presente.

A variável Capacidade aparece no modelo com a hipótese "de que arenas maiores atendem clubes com maior demanda, seja por possuir maior torcida, estar localizado em cidades mais populosas ou por outros fatores não identificados" (SOUZA, 2004, p. 61).

A variável Promovido foi acrescentada ao modelo sob a hipótese de que o time que conseguiu ascensão na temporada anterior atrai um maior público para a temporada atual.

Clubes como Flamengo, Corinthians, São Paulo, Palmeiras, Vasco, Botafogo e Fluminense apresentam uma torcida com mais de $40 \%$ fora de seus estados de origem. Assim, assume-se a hipótese de que jogos em que esses times são visitantes afetam significativamente a demanda por jogos do campeonato brasileiro, independente da série disputada. Dessa forma, a variável Grande será acrescentada ao modelo.

Posição é uma variável que representa a colocação do time da casa no jogo $i$ e foi utilizada sob a hipótese de que quanto mais longe das primeiras colocações menor será a demanda. 
Para captar o efeito de avanço do campeonato, foi utilizada a variável referente à rodada em que a partida ocorreu, sob a hipótese de que ao se aproximar do fim do campeonato a demanda por jogos aumenta, visto que as partidas se tornam mais decisivas.

No Brasil, devido à realização da Copa do Mundo de 2014, doze estádios foram reformulados ou construídos com os novos conceitos de arenas, que trazem mais conforto e segurança aos torcedores. Em 2013, seis destes estádios tiveram jogos do campeonato brasileiro. Dessa maneira, será utilizada uma variável dummy para o caso de a partida ter ocorrido em uma dessas arenas.

O tamanho da torcida também está presente no modelo para captar a capacidade de mercado. Assim, foi utilizado o tamanho da torcida do time da casa.

A variável $\mathrm{PFC}$ relaciona-se à porcentagem de assinantes, por estado, do canal pay-per-view Premiere Futebol Clube, que faz transmissões de jogos do campeonato brasileiro de futebol, funcionando, assim, como um bem substituto da venda de ingressos.

Uma variável dummy referente à chance de o time da casa se classificar para a Copa Libertadores foi empregada no modelo.

Foram acrescentadas também variáveis referentes à diferença de pontos e posição dos times envolvidos na partida e o quadrado destas variáveis, pois, de acordo com Souza (2004), a relação entre essas variáveis é quadrática. E, como afirma Bortuluzzo, Laropoli e Machado (2011), esta variável é importante, pois a importância do jogo para o time da casa é relevante para entender a demanda por ingressos. Logo, espera-se que quanto menor a diferença de posição e pontos entre os times, maior será a procura por ingressos.

Por último, foram acrescentadas variáveis dummies para caso o jogo tenha ocorrido no fim de semana e à tarde, pois, como afirmam García e Rodríguez (2001), o horário e dia da realização da partida são importantes para a explicação da demanda.

O Quadro 2 traz uma síntese com as variáveis explicativas usadas no modelo econométrico, os autores em que estão embasadas, a forma em que os dados foram tratados e o efeito esperado.

Para estimar a função de demanda por futebol será utilizado o método dos mínimos quadrados ordinários, que, segundo Gujarati (2002), é um dos melhores métodos para uma análise de regressão. A equação a ser estimada é dada a seguir:

$$
Y_{i}=\alpha_{0}+\alpha_{1} X_{1 i}+\alpha_{2} X_{2 i}+\alpha_{3} X_{3 i}+\ldots+\alpha_{16} X_{16 i}+\varepsilon_{i}
$$

Em (1), $Y_{i}$ é a variável dependente dada pelo público pagante na partida $i$ e $X$ são as variáveis explicativas, listadas no quadro 1, em ordem de utilização. 


\section{Quadro 2 - Síntese das variáveis utilizadas no modelo econométrico}

\begin{tabular}{|c|c|c|c|}
\hline $\begin{array}{l}\text { Variáveis } \\
\text { explicativas }\end{array}$ & Referencial teórico & Operacionalização & $\begin{array}{l}\text { Efeitos } \\
\text { esperados }\end{array}$ \\
\hline $\begin{array}{l}\log \\
(\text { Preço) }\end{array}$ & $\begin{array}{l}\text { Dobson e Goddard (2001); García e } \\
\text { Rodríguez (2001); Madalozzo (2008); e } \\
\text { Bortoluzzo, Laropoli e Machado (2011) }\end{array}$ & $\begin{array}{l}\text { Será usado o preço médio (razão entre a arreca- } \\
\text { dação total da bilheteria no jogo analisado e o } \\
\text { público pagante total). }\end{array}$ & - \\
\hline $\log (\text { preço })^{\wedge} 2$ & & $\begin{array}{l}\text { Será utilizado o quadrado da variável } \\
\text { Log(preço). }\end{array}$ & + \\
\hline $\begin{array}{l}\log \\
\text { (Renda) }\end{array}$ & $\begin{array}{l}\text { García e Rodríguez (2001); Souza } \\
\text { (2004); Madalozzo (2008); e Bortoluzzo, } \\
\text { Laropoli e Machado (2011) }\end{array}$ & $\begin{array}{l}\text { Será usada a renda média por domicílio da } \\
\text { cidade em que a partida ocorreu. }\end{array}$ & - \\
\hline Rival & $\begin{array}{l}\text { Souza (2004); Madalozzo (2008); e Bor- } \\
\text { toluzzo, Laropoli e Machado (2011) }\end{array}$ & $\begin{array}{l}\text { Será utilizada uma variável dummy com valor } 1 \\
\text { para o caso de os times serem da mesma cidade } \\
\text { e } 0 \text { caso contrário. }\end{array}$ & + \\
\hline $\begin{array}{l}\text { Log } \\
\text { (Capacidade) }\end{array}$ & $\begin{array}{l}\text { Souza (2004); Madalozzo (2008); e Bor- } \\
\text { toluzzo, Laropoli e Machado (2011) }\end{array}$ & $\begin{array}{l}\text { Será utilizada a capacidade do estádio em que o } \\
\text { jogo ocorreu. }\end{array}$ & + \\
\hline Grande & $\begin{array}{l}\text { Souza (2004); Madalozzo (2008); e Bor- } \\
\text { toluzzo, Laropoli e Machado (2011) }\end{array}$ & $\begin{array}{l}\text { Será utilizada uma variável dummy com valor } \\
1 \text { para caso o time visitante seja Flamengo, Co- } \\
\text { rinthians, São Paulo, Palmeiras, Vasco, Botafogo } \\
\text { ou Fluminense. }\end{array}$ & + \\
\hline Promovido & $\begin{array}{l}\text { Dobson e Goddard (2001); Souza } \\
\text { (2004); Madalozzo (2008); e Bortoluzzo, } \\
\text { Laropoli e Machado (2011) }\end{array}$ & $\begin{array}{l}\text { Será utilizada uma variável dummy com valor } 1 \\
\text { caso o time mandante tenha sido promovido na } \\
\text { temporada anterior e } 0 \text { caso contrário. }\end{array}$ & + \\
\hline PFC & - & $\begin{array}{l}\text { Será utilizado o percentual de assinantes do } \\
\text { canal Premiere Futebol Clube, por estado. }\end{array}$ & - \\
\hline Rodada & Souza (2004) & $\begin{array}{l}\text { Será utilizado o número da rodada em que a } \\
\text { partida ocorreu. }\end{array}$ & + \\
\hline Fim & $\begin{array}{l}\text { Madolozzo(2008); Bortoluzzo, Laropoli } \\
\text { e Machado (2011) }\end{array}$ & $\begin{array}{l}\text { Será utilizada uma variável dummy com valor } 1 \\
\text { caso o jogo ocorra no final de semana e } 0 \text { caso } \\
\text { contrário. }\end{array}$ & \\
\hline Posição & $\begin{array}{l}\text { Dobson e Goddard (2001); Madalozzo } \\
\text { (2008); Bortoluzzo, Laropoli e Machado } \\
(2011)\end{array}$ & $\begin{array}{l}\text { Será utilizada a posição na tabela do time } \\
\text { mandante da partida. }\end{array}$ & - \\
\hline Pontos & Souza $(2004)$ & $\begin{array}{l}\text { Será utilizada a diferença de pontos até a } \\
\text { realização da partida entre o time mandante e } \\
\text { visitante. }\end{array}$ & - \\
\hline $\begin{array}{l}\log \\
\text { (Torcida) }\end{array}$ & - & $\begin{array}{l}\text { Será utilizado o número de torcedores do time } \\
\text { da casa, no estado em que o jogo ocorreu. }\end{array}$ & + \\
\hline Arenas & 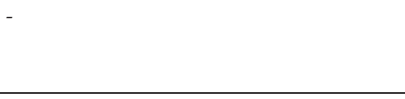 & $\begin{array}{l}\text { Será utilizada uma variável dummy com valor } \\
1 \text { caso a partida tenha sido realizada em dos } \\
\text { novos estádios brasileiros. }\end{array}$ & + \\
\hline Libertadores & $\begin{array}{l}\text { Madalozzo (2008); Bortoluzzo, Laropoli } \\
\text { e Machado (2011) }\end{array}$ & $\begin{array}{l}\text { Será utilizada uma variável dummy com valor } \\
1 \text { caso o time esteja entre os seis primeiros } \\
\text { colocados e } 0 \text { caso contrário. }\end{array}$ & + \\
\hline
\end{tabular}

Fonte: Elaboração própria.

\section{ANÁLISE DE RESULTADOS}

Esta seção consiste na avaliação dos resultados obtidos na equação de demanda estimada por Mínimos Quadrados Ordinários (MQO) para os jogos do campeonato brasileiro de 2013. E divide-se em duas subseções, a primeira traz uma análise dos fatores econômicos, já a segunda se atém a analisar os resultados referentes à qualidade da partida e incerteza do resultado. 


\subsection{FATORES ECONÔMICOS}

As variáveis utilizadas no grupo de fatores econômicos, preço e seu quadrado, bem como renda, mostraram-se estatisticamente significantes ao nível de 5\%.

No caso do preço e seu quadrado, as elasticidades obtidas foram de -1,28 e 0,18, respectivamente. Esse resultado mostra que a demanda por futebol no Brasil diminui, com um aumento no preço, mas apenas até certo ponto, quando passa a crescer com uma elevação no preço. Este fenômeno pode ser explicado pela violência nos estádios brasileiros. Pois, dado um aumento do preço, a presença de torcedores com uma faixa de renda menor diminui. Isso, somado ao preconceito existente no Brasil, de que os mais pobres estão sempre ligados à violência, eleva a demanda por jogos na camada mais rica da população. O que é corroborado pelo resultado encontrado na renda, que obteve uma elasticidade de 1,17, mostrando que o futebol é um bem de luxo, pois, segundo Varian (2006), esse tipo de bem é encontrado quando a demanda aumenta mais que proporcionalmente a um aumento na renda.

Os resultados referentes à variável preço mostram que a função demanda por futebol é não homogênea, o que implica, segundo Simon e Blume (1994), que a demanda não depende linearmente do preço. Ainda pode ser observado o conceito de preço excludente, ou seja, a partir de determinado preço, a procura por jogos do campeonato brasileiro aumenta devido à exclusão do consumo de indivíduos com renda inferior e que estão ligados à violência nos estádios brasileiros.

\subsection{QUALIDADE DA PARTIDA, FATORES ESTRUTURAIS E INCERTEZA DO RESULTADO}

Outros fatores que se mostraram estatisticamente significantes para o Brasil estão relacionados à qualidade da partida e incerteza do resultado.

Com relação à qualidade da partida e a incerteza do resultado, as variáveis Grande e Rival mostram que, caso o time visitante seja do Rio de Janeiro ou São Paulo, a demanda aumenta em cerca de $20 \%$, enquanto se o jogo é considerado clássico (com clubes da mesma cidade) a procura por ingressos aumenta pela metade.

Estes resultados mostram que no futebol brasileiro os atributos dos times visitantes influenciam na procura por partidas. Enquanto em relação aos atributos do time da casa apenas a variável Promovido mostrou-se significativa, tendo como resultado um aumento de 40\%, em média, nos jogos em que o time mandante tenha conseguido o acesso da segunda divisão na temporada anterior.

No grupo de fatores estruturais, o tamanho da torcida, o dia de realização da partida e o fato de as mesmas serem realizadas nas novas arenas construídas para Copa 
do Mundo de 2014, mostraram ter um impacto positivo na demanda por jogos do campeonato brasileiro de futebol. Com relação ao tamanho da torcida os resultados mostram que quanto maior a torcida, maior será o público presente no estádio. Ainda é possível observar que os jogos realizados nos novos estádios têm, em média, uma demanda de $1 \frac{1}{2}$ maior. Já caso a partida seja realizado nos fins de semana a tarde, a procura por jogos é, em média, 20\% maior.

Os resultados da equação estimada por Mínimos Quadrados Ordinários para a equação de demanda podem ser encontrados na Tabela 1 .

O modelo não apresentou problemas de acordo com os testes de Bresch-Godfrey para heterocedasticidade e de Reset-Ramsey para especificação do modelo.

\begin{tabular}{|c|c|}
\hline Variáveis & Coeficientes \\
\hline Constante & $\begin{array}{c}-2,8312 \\
(0,17)\end{array}$ \\
\hline (Preço) & $\begin{array}{c}-1,2808^{*} \\
(0,00)\end{array}$ \\
\hline$(\text { Preço })^{\wedge} 2$ & $\begin{array}{c}0,1884^{*} \\
(0,00)\end{array}$ \\
\hline (Renda) & $\begin{array}{c}1,1702^{*} \\
(0,00)\end{array}$ \\
\hline Promovido & $\begin{array}{c}0,4235^{*} \\
(0,00)\end{array}$ \\
\hline PFC & $\begin{array}{l}-0,0665 \\
(0,22)\end{array}$ \\
\hline Rodada & $\begin{array}{c}0,0095^{*} \\
(0,03)\end{array}$ \\
\hline Fim & $\begin{array}{c}0,1755^{*} \\
(0,02)\end{array}$ \\
\hline Rival & $\begin{array}{c}0,4358^{*} \\
(0,00)\end{array}$ \\
\hline Posição & $\begin{array}{c}-0,0024 \\
(0,83)\end{array}$ \\
\hline Libertadores & $\begin{array}{c}0,0475 \\
(0,73)\end{array}$ \\
\hline Pontos & $\begin{array}{c}-0,0083 \\
(0,20)\end{array}$ \\
\hline Grande & $\begin{array}{c}0,1769^{*} \\
(0,04)\end{array}$ \\
\hline (Torcida) & $\begin{array}{c}0,2604^{*} \\
(0,00)\end{array}$ \\
\hline Arenas & $\begin{array}{c}0,5585^{*} \\
(0,00)\end{array}$ \\
\hline R-Squared & 0,4043 \\
\hline
\end{tabular}

Notas: * Significante a $5 \%$.

Fonte: Elaboração própria. 


\section{CONCLUSÕES}

O futebol constitui uma atividade econômica muito significativa em vários países. Deve, portanto, ser estudado em uma perspectiva sistêmica, capaz de compreender toda sua cadeia produtiva. Devido à importância desse esporte e as divergências acadêmicas referentes à variável preço, este estudo buscou identificar os fatores que influenciam a demanda por jogos de futebol no Brasil, bem como a relação da procura com o preço.

A partir de um modelo econométrico estimado por Mínimos Quadrados Ordinários (MQO) foi possível identificar a relação entre o preço e a demanda por futebol, assim como alguns dos fatores que levam os torcedores a demandar deste bem. Também foi possível verificar o impacto dos fatores econômicos na procura por partidas de futebol, bem como observar o impacto dos novos estádios nesta demanda. Cumprindo, desta forma, os objetivos deste trabalho.

Os resultados corroboram as hipóteses elencadas anteriormente de que a função demanda por este bem é não-linear, não homogênea, bem como é função de fatores econômicos.

O estudo mostrou que as novas arenas elevaram em cerca de $55 \%$ a demanda por jogos do campeonato brasileiro. Em 2014, mais seis arenas foram reformadas ou construídas, o que provavelmente acarretará em um aumento maior na procura por jogos no Brasil nesse ano. Acarretando, consequentemente, em uma elevação na receita proveniente de bilheteria dos clubes brasileiros. Este impacto dá-se pelo fator curiosidade dos torcedores em conhecer os novos estádios, que prometem mais conforto e segurança. Mas, é esperado que este impacto não perdure, dado o fim do fator curiosidade. Assim como aconteceu na Inglaterra na década de 2000, que após um aumento exponencial na década de 1990, com a reforma dos seus estádios, apresentou um público constante.

Os achados deste estudo contribuem para o aumento da literatura sobre a Economia do Esporte, mostrando a importância do futebol como indústria. Contribuem, ainda, para que os agentes envolvidos nesta indústria possam tomar decisões mais eficientes, visando ao aumento de seus resultados. É possível verificar que no Brasil, por exemplo, se os clubes aumentarem o preço dos ingressos, aumentarão suas receitas.

As limitações encontradas neste trabalho consistem na indisponibilidade de dados para campeonatos anteriores, o que inviabilizou a extensão da pesquisa para um horizonte maior de tempo. Registra-se, também, a falta de informações sobre violência nos estádios brasileiros, que pode ser um dos fatores mais importantes para explicar a presença de público.

Sugere-se que o estudo sirva de base comparativa para futuros trabalhos sobre a demanda por jogos do campeonato brasileiro e inglês. Há também a possibilidade de 
se verificar o impacto da Copa do Mundo FIFA 2014 na procura por partidas do campeonato brasileiro. Esta pesquisa pode, também, servir de parâmetro para estudos de campeonatos nacionais de outros países como Espanha, e Alemanha, que apresentam uma boa média de público nos estádios, analisando de que forma cada fator utilizado neste trabalho impacta a demanda por jogos nesses países.

Ainda sugere-se uma análise da função demanda para o futebol nos demais países, para que possa ser verificado se a demanda por futebol é não-homogênea, assim como acontece no Brasil. Para a teoria econômica, sugere-se, ainda, verificar a ocorrência desse fenômeno em outros bens.

\section{REFERÊNCIAS}

BELO, E.; PAOLOZZI, V. Futebol faz 150 anos e movimenta até US\$ 1 tri. Valor Econômico, Ano 14, n. 3371, 25/10/2013. Disponível em: <https://www.pressreader.com/brazil/valor-econ\% C3\%B4mico/20131025/281492159058805>. Acesso em: 28 out. 2013.

BORTOLUZZO, A. B.; LAROPOLI, P. T.; MACHADO, S. J. Demand for Brazilian soccer: A censored model approach. Insper Working Paper, v. 237, p. 1-18, 2011.

BURAIMO, B.; SIMMONS, R. Market size and attendance in English Premier League football. International Journal of Sport Management and Marketing, v. 6, n. 2, p. 200-214. 2009.

CBF - CONFEDERAÇÃO BRASILEIRA DE FUTEBOL. Competições. Brasileiro Série A. Ano 2012. [On-line] CBF, 2012. Disponível em: <http://www.cbf.com.br/Competi\%C3\%A7\%C3\%B5es/S\%C3\%A9rie\%20A/Tabela/2012>. Acesso em: 20 fev. 2014.

DELL'OSSO, F.; SZYMANSKI, S. Who are the champions? An analysis of football and architecture. Business Strategy Review Summer, v. 2, n. 2, p. 113-130. 1991. Disponível em: <http:// onlinelibrary.wiley.com/doi/10.1111/j.1467-8616.1991.tb00155.x/abstract?deniedAccessC ustomisedMessage $=\&$ userIsAuthenticated=false $>$. Acesso em: 20 abr. 2014 .

DOBSON, S.; GODDARD, J. The economics of football. Cambridge: Cambridge University Press, 2001.

DUCREY, P.; FERREIRA, C. E.; HUERTA, G.; MARSTON; K. T. Revisiting UEFA's Governance Model: adaptations for the challenges of modern football. Final Work - International Master (MA) in Management, Law and Humanities Sports. Neuchâtel, SW: Centre International D'Etude Du Sport, 2003. Disponível em: <http://www.goldengoal.com.br/ggsv/html/ publicacoes/papers_artigos/revisiting_uefa_governance_model.pdf $>$. Acesso em: 12 jan. 2014.

GARCÍA, J.; RODRÍGUEZ, P. The determinants of football match attendance revisited: empirical evidence from the Spanish football league. Economics Working Papers, Department of Economics and Business, University Pompeu Fabra, 2001.

GIL, A. C. Como elaborar projetos de pesquisa. 5. ed. São Paulo: Atlas, 2010.

GUJARATI, D. Econometria básica. São Paulo: Makron Books, 2002. 
IBGE - INSTITUTO BRASILEIRO DE GEOGRAFIA E ESTATÍSTICA. IBGE Cidades@. [Online] IBGE. Disponível em: <http://www.ibge.gov.br/cidadesat/index.php>. Acesso em: 23 fev. 2014

MADALOZZO, R. A model of attendance demand at the Brazilian football league. Insper Working Paper, n. 113, 2008.

O'CONNOR, J. G. Do league ranking, promotion and relegation affect football stadium attendance? An empirical investigation into the English football league. Nottingham, UK: University of Nottingham, 2009.

PINDYCK, R. S.; RUBINFELD, D. L. Microeconomia. 7. ed. Boston: Pearson, 2009.

PLURICONSUlTORIA. Relatório. [On-line] Pluri Consultoria. Disponível em: <http://www. pluriconsultoria.com.br/relatorios.php>. Acesso em: 20 dez. 2013.

RICHARDSON, R. J. Pesquisa social: métodos e técnicas. 3. ed. São Paulo: Atlas, 2007.

ROTTENBERG, S. The baseball players' labor market. Journal of Political Economy, v. 62, p. 242-258, 1959.

SILVA, E. L.; MENEZES, E. M. Metodologia da pesquisa e elaboração de dissertação. Florianópolis: UFSC, 2001.

SIMON, C. P.; BLUME, L. Mathematics for economists. New York: Norton \& Company, 1994.

SOUZA, F. A. P. Um estudo sobre a demanda por jogos de futebol nos estádios brasileiros. Dissertação (Mestrado em Administração) - Departamento de Administração, Faculdade de Economia e Administração, Universidade da São Paulo, 2004. Disponível em: <http://www. teses.usp.br/teses/disponiveis/12/12139/tde-21072004-151604/pt-br.php>. Acessado em: 31 jan. 2014.

VARIAN, Hal. R. Microeconomia: uma abordagem moderna. 7. ed. Rio de Janeiro: Elsevier, 2006. 